\title{
A stack multilayer high reflectance optical filter produced on polyester substrate with the PECVD technique
}

\author{
J. KOWALSKI*, H. SZYMANOWSKI, A. SOBCZYK-GUZENDA, and M. GAZICKI-LIPMAN
}

Institute of Materials Science and Engineering, Technical University of Łódź, 1-15 Stefanowskiego St., 90-924 Łódź, Poland

\begin{abstract}
The present work reports results of an effort to produce a stack multilayer optical filter on a poly(ethylene terephtalate) (PET) substrate, using a PECVD technique. Titanium dioxide type of material $\left(\mathrm{n}_{550}=2.3\right)$ has been selected for high refractive index layers while that of silicon dioxide type $\left(\mathrm{n}_{550}=1.4\right)$ served as low refractive index films. For a synthesis of the former material, titanium tetrachloride with an excess of gaseous oxygen was taken as a precursor system, and a mixture of oxygen and hexamethyldisiloxane (HMDSO) was used as a precursor system for a deposition of the latter one. The entire deposition process was carried out in the same parallel plate PECVD reactor, with all the consecutive layers being synthesized in one vacuum run.

In the first part of the work, the deposition processes of both types of materials were optimized separately using polyester film as a substrate. The main goal of this step was to obtain high refractive index and low refractive index materials of good optical quality, remaining as close as possible to that of, respectively, titanium dioxide and silicon dioxide, without jeopardizing the optical quality of the polymer support.

A construction of the filter was the next stage of the work. The design concerned high reflectance (HR) type filter consisting of five high refractive index layers, separated by four low refractive index films. Before an actual deposition, a performance of such system had been simulated, using the TFCalc ${ }^{\mathrm{TM}} 3.5$ optical software. As a final step, the real structure, consisting of nine films, was produced, and the optical properties of the so obtained filter have been compared with those of the simulated system.
\end{abstract}

Key words: interference filter, titanium dioxide, silicon dioxide, polyester substrate.

\section{Introduction}

Polymer materials play an ever increasing role in the modern world of high technology. Their attractiveness is primarily due to low density, high flexibility and, last but not least, low costs. This trend is also clearly observed in optics and optoelectronics, where polymers begin to replace such standard substances as glass. However, one of their most significant set-backs is thermal sensitivity of these materials, which places on them a rigid requirement of low temperature processing.

The technology of thin film optical devices, such as filters, mirrors or waveguides, involves a fabrication of stack multilayer structures comprised of alternated layers of low and high refractive index materials. For the purpose of their deposition on glass or other inorganic materials, usually either thermal CVD or sputtering technique is used. However, these techniques require that the substrate withstands substantially elevated temperatures and, therefore, they are not suitable for polymer substrates. Plasma enhanced chemical vapor deposition (PECVD) method, with its low temperature deposition conditions, is a good candidate for filling that gap. Additionally, this technique gives few more advantages such as very good uniformity on 3D objects, high deposition rates and good films quality.

Due to their high optical quality and a substantial difference in the values of their refractive indices (n) silicon dioxide and titanium dioxide make one of the most popular combination of low and high $\mathrm{n}$ materials [1]. A preparation of amorphous oxides on polymer substrates by PECVD method is known. Applications of silicon dioxide films produced in this way comprise diffusion barrier coatings [2, 3] and protective, scratch resistant coatings [4]. Depending on PECVD process parameters one is able to deposit amorphous films with good optical properties [5, 6] and thus to produce high quality optical filters [7].

In the present work, PECVD deposition of silicon dioxide films from hexamethyldisiloxane (HMDSO) and titanium dioxide layers from titanium tetrachloride is investigated, using poly(ethylene terephtalate) (PET) foils as substrates. As the main goal of the work, an effort to manufacture a stack interference filter, comprised of five titanium oxide and four silicon oxide layers, is undertaken.

\section{Experiments}

A low volume (approximately $2 \mathrm{dm}^{3}$ ) radio frequency PECVD reactor was used in this work. The chamber of this reactor consists of two parallel stainless steel electrodes and a glass cylinder that separates them. The reagents are introduced to the chamber through a shower type electrode, with separate supply lines for both precursor compounds and oxygen gas. The lower electrode is used to supply the system with RF power using a Plasma Products, model RF5S power generator and a self-made matching circuit. A schematic view of the reactor is presented below, in Fig. 1 .

*e-mail: jacek_k@wp.pl 


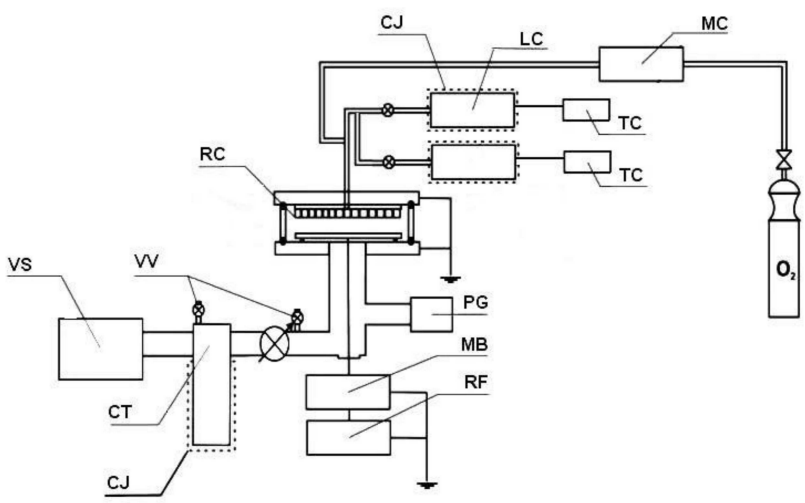

Fig. 1. A schematic representation of PECVD reactor system. System description: MC - mass flow controllers, LC - container with liquid precursor compounds, TC - temperature controller, $\mathrm{RC}-$ reactor chamber, PG - pressure gauge, VS - vacuum system, MB matchbox, RF - RF generator, CT - cold trap, CJ - cooling jacket, VV - venting valves

In an early phase of the work, prior to any attempts to manufacture a filter, the deposition process of both types of materials was investigated in order to optimize their operational parameters. In all the preliminary work, the same $0.2 \mathrm{~mm}$ thick poly(ethylene terephtalate) (PET) foil, as that intended for the filter support, was used as a substrate. The subject of the optimization concerned deposition of films of the best possible optical quality with as little as possible damage done to the optical quality of the substrate.

As a precursor system for silicon dioxide deposition a mixture of hexamethyldisiloxane (HMDSO $-\mathrm{C}_{6} \mathrm{H}_{18} \mathrm{OSi}_{2}$ ) and oxygen was applied. HMDSO of purity $98.5 \%$ from SigmaAldrich Chemie was used without further purification. The RF power of glow discharge was varied between 100 and 400 Watts, while oxygen to HMDSO ratio was altered from 5:1 to 40:1. All the deposition processes were carried out with a constant temperature of liquid hexamethyldisiloxane container equal $0^{\circ} \mathrm{C}$.

Titanium dioxide layers were produced using titanium tetrachloride $\left(\mathrm{TiCl}_{4}\right)$ from Ridel de Haën Company and oxygen gas. $\mathrm{TiCl}_{4}$ was introduced to the system without any additional purification and the temperature of its container was also kept at a constant temperature of $0^{\circ} \mathrm{C}$. Again in this case the operational parameters comprised: RF power varied from $100 \mathrm{~W}$ to $400 \mathrm{~W}$ and oxygen to precursor ratio between 5:1 and 40:1.

The designed structure was a nine layer stack interference system consisting of five high refractive index films separated by four low refractive index films. It was a high reflectance (HR) filter with maximum reflectance at $583 \mathrm{~nm}$ amounting to $96.1 \%$. Before an actual deposition, this system was simulated with the help of TFCalc ${ }^{\mathrm{TM}} 3.5$ by Software Spectra, Inc., popular software package successfully used for theoretical calculations in a number of studies [8-10].

After computer simulation, a real structure was produced in one vacuum run. Prior to the deposition, polymer substrates were exposed to argon plasma etching pretreatment for 5 minutes at $100 \mathrm{~W}$ of RF power.
Single films and filter optical properties were characterized by means of Varian Cary 5000 UV-Vis spectrometer.

For the morphological studies and chemical composition determination scanning electrons microscope Jeol JSM 6380LA equipped with energy dispersive X-rays spectrometer was used. Observations were carried out with low acceleration voltages of $5 \mathrm{kV}$ for uncoated samples or $15 \mathrm{kV}$ after gold coating and in a low vacuum mode.

\section{Results}

3.1. Low refractive index material. Deposition of silicon dioxide films on polyester substrates was investigated with the RF power of the discharge and oxygen to HMDSO ratio used as operational parameters. Since, for constant process conditions, film thickness has been found to be a linear function of deposition time, studies of deposition rate dependence on these parameters have been performed at a standard deposition time of 30 minutes. The results of deposition rate dependence on power are shown in Fig. 2, while Fig. 3 presents the relationship of film thickness on the oxygen to HMDSO ratio. An example of film thickness linearity with time is presented in the window of Fig. 2.

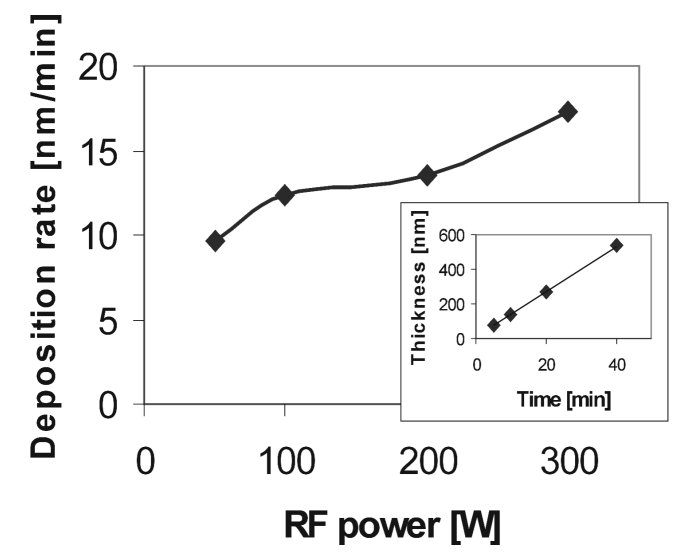

Fig. 2. Deposition rate dependence on RF power for the silicon oxide deposition system at the $\mathrm{O}_{2} / \mathrm{HMDSO}$ ratio of 20:1. An example of film thickness linearity with deposition time is presented in the window

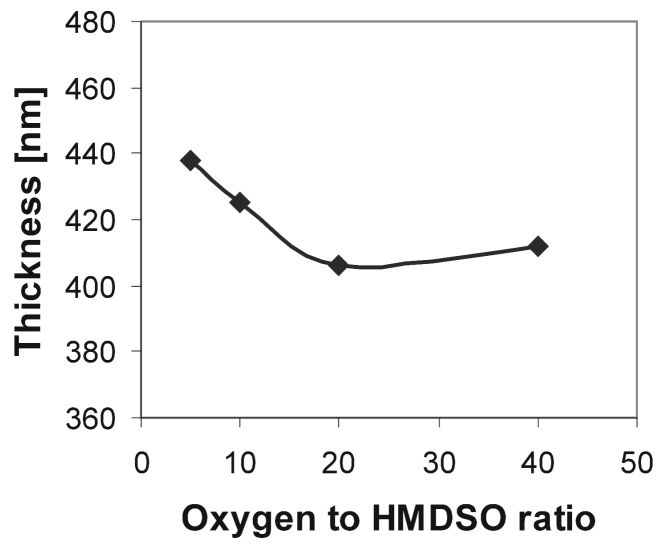

Fig. 3. Film thickness dependence the $\mathrm{O}_{2} / \mathrm{HMDSO}$ ratio system at the RF power of 200 Watt for the silicon oxide deposition (deposition time of 30 minutes) 
Although the preliminary investigation was carried out within the range of RF power between 50 and 400 Watt, in Fig. 2 the upper limit of this parameter is only 300 Watt. This is due to the fact that, having been fairly satisfactory for lower power values, the films quality dramatically decreased at the power of $400 \mathrm{~W}$. All layers produced with $300 \mathrm{~W}$ of RF power and below exhibit continuous, smooth and free from defects surface, an example of which is presented in Fig. 4a. As a contrast to that, the film deposited at the RF power of 400 Watt, shown in Fig. 4b, exhibits a completely different, very porous structure. Since the negative effect of high energetic condition is not observed in the case of other substrates, such as silicon wafers and glass plates, a conclusion has been reached that it is straightforwardly connected with the degradation, probably of an oxidative nature, of polymer substrates.

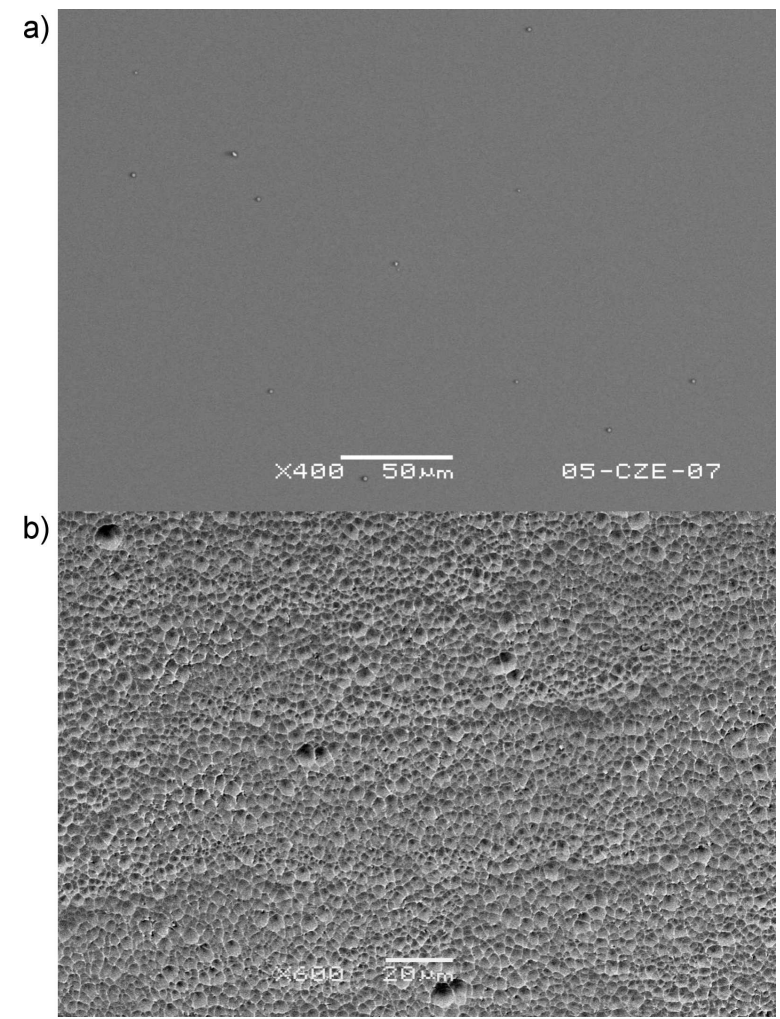

Fig. 4. Surface of silicon oxide films produced at RF power of 200 Watt (a) and 400 Watt (b)

Chemical composition of silicon oxide films in relation to RF power of their deposition is presented in Table 1. We can see in the table that oxygen to silicon ratio falls in the range of 1.73-1.85 and increases with the RF power, for 300 Watt of deposition power acquiring nearly that of silicon dioxide. The films also contain certain amount of carbon, whose concentration decreases with an increasing RF power. Methyl groups, present in the molecule of HMDSO, constitute a source of carbon, which represents an organic fraction present in the structure of an oxide. A diminishing content of this fraction with an increasing power of the glow discharge is a common finding in a PECVD deposition of silicon based thin film materials, synthesized from organosilicon precursors.
Table 1

Chemical composition of silicon dioxide films, produced at different RF power of deposition and at the $\mathrm{O}_{2} / \mathrm{HMDSO}$ ratio of 20:1, with the values of their refractive index at $550 \mathrm{~nm}$

\begin{tabular}{cccccc}
\hline \hline $\begin{array}{c}\text { RF power } \\
{[\mathrm{W}]}\end{array}$ & $\begin{array}{c}\mathrm{O} \\
{[\text { At.\%] }}\end{array}$ & $\begin{array}{c}\mathrm{Si} \\
{[\text { At.\%] }]}\end{array}$ & $\begin{array}{c}\mathrm{C} \\
{[\text { At.\%] }}\end{array}$ & O/Si & $\begin{array}{c}\text { Refractive } \\
\text { index }\end{array}$ \\
\hline 50 & 58.0 & 33.6 & 8.4 & 1.73 & - \\
\hline 100 & 60.9 & 33.8 & 5.3 & 1.80 & $1.39 \pm 0,03$ \\
\hline 200 & 61.6 & 34.6 & 3.8 & 1.78 & $1.40 \pm 0,04$ \\
\hline 300 & 63.7 & 34.4 & 1.9 & 1.85 & $1.41 \pm 0,07$ \\
\hline
\end{tabular}

Chemical composition of the films also changes with different oxygen to HMDSO ratio. The respective data are presented in Table 2. As the oxygen plasma is known to impact on precursor decomposition we are observing a decrease of carbon content with increasing $\mathrm{O}_{2}$ to HMDSO ratio, with a simultaneous increase of oxygen content in the films.

Table 2

Chemical composition of silicon dioxide films, produced at different oxygen to HMDSO ratios and at the RF power of 200 , with the values of their refractive index at $550 \mathrm{~nm}$

\begin{tabular}{cccccc}
\hline \hline $\mathrm{O}_{2} / \mathrm{HMDSO}$ & $\begin{array}{c}\mathrm{O} \\
{[\text { At.\%] }}\end{array}$ & $\begin{array}{c}\mathrm{Si} \\
{[\text { At.\%] }}\end{array}$ & $\begin{array}{c}\mathrm{C} \\
{[\text { At.\%] }}\end{array}$ & O/Si & $\begin{array}{c}\text { Refractive } \\
\text { index }\end{array}$ \\
\hline 5 & 60.2 & 35.4 & 4.4 & 1.70 & $1.47 \pm 0,05$ \\
\hline 10 & 60.9 & 34.8 & 4.3 & 1.75 & $1.43 \pm 0,03$ \\
\hline 20 & 60.8 & 34.0 & 4.1 & 1.79 & $1.40 \pm 0,05$ \\
\hline 40 & 63.8 & 34.4 & 1.8 & 1.85 & $1.39 \pm 0,04$ \\
\hline
\end{tabular}

Based on the analysis of the above data the following parameters have been selected for the deposition of the silicon dioxide type low refractive index component of the HR filter: $200 \mathrm{~W}$ of $\mathrm{RF}$ power and $\mathrm{O}_{2} / \mathrm{HMDSO}$ ratio of 20:1. For these parameters deposition rate amounts to approximately $13,5 \mathrm{~nm}$ per minute. The optical quality of this material, in the form of its transmission spectrum, is presented in Fig. 5.

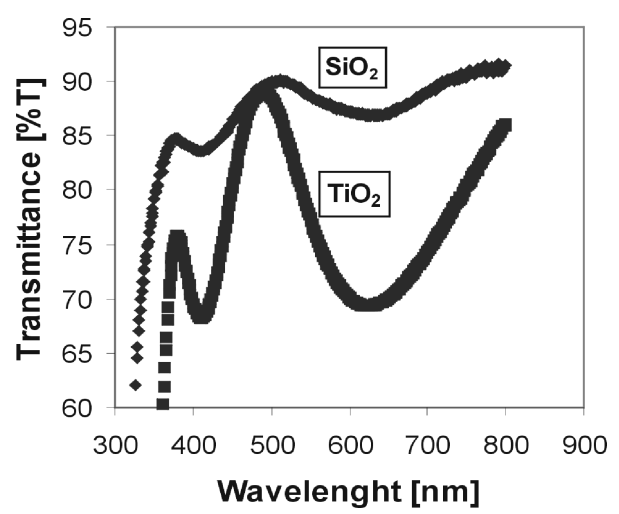

Fig. 5. Transmission spectrum of silicon oxide film, produced at RF power of 200 Watt and $\mathrm{O}_{2}$ to HMDSO ratio of 20:1 together with transmission spectrum of titanium oxide film, produced at RF power of 200 Watt and $\mathrm{O}_{2}$ to $\mathrm{TiCl}_{4}$ ratio of $40: 1$

3.2. High refractive index material. In terms of their synthesis in this work, titanium dioxide films exhibit similar behavior as silicon oxide materials - a good quality within 100$300 \mathrm{~W}$ range of RF power and unacceptable structure above 
that range. In addition, the process of deposition has also certain influence on the surface of polymer substrate, producing the same slightly hazy effect, independent of deposition time. This phenomenon is very likely due to an impact of the aggressive precursor compound, namely titanium tetrachloride, which, in the environment of oxygen plasma, initiates reactive etching of the polymer before any appreciable amount of oxide is deposited to protect the surface from further etching.

Since, again in this case, film thickness is a linear function of deposition time for constant process conditions, deposition rate dependence on the RF power has been determined at a standard deposition time of 30 minutes. Figure 6 presents this dependence, with the plot in a window giving an example of film thickness linearity with time. The studies of deposition rate dependence on the $\mathrm{O}_{2} / \mathrm{TiCl}_{4}$ ratio have not been performed in this case, since that of 40:1 proved to be an optimum on the basis of the very quality of the films. Higher values of this ratio yielded films heavily contaminated with powder product, while hardly any appreciable amount of material was deposited at lower proportions.

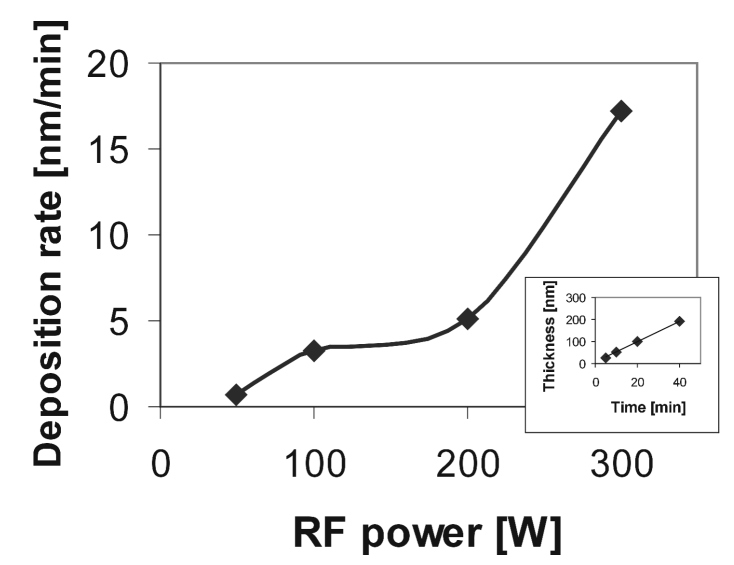

Fig. 6. Deposition rate dependence on RF power for the titanium oxide deposition system at the $\mathrm{O}_{2} / \mathrm{TiCl}_{4}$ ratio of 40:1. An example of film thickness linearity with deposition time is presented in the window

As far as the films produced at the above composition of precursor mixture and different plasma power are concerned, a strong spread of their chemical composition followed by large differences in refractive index is observed. The respective data are presented in Table 3.

Table 3

Chemical composition of titanium dioxide films, produced at different RF power of deposition and at the $\mathrm{O}_{2} / \mathrm{TiCl}_{4}$ ratio of $40: 1$, with the values of their refractive index at $550 \mathrm{~nm}$

\begin{tabular}{cccccc}
\hline \hline $\begin{array}{c}\text { RF power } \\
{[\mathrm{W}]}\end{array}$ & $\begin{array}{c}\mathrm{O} \\
{[\text { At.\% }]}\end{array}$ & $\begin{array}{c}\mathrm{Ti} \\
{[\text { At.\% }]}\end{array}$ & $\begin{array}{c}\mathrm{Cl} \\
{[\text { At.\% }]}\end{array}$ & O/Ti & $\begin{array}{c}\text { Refractive } \\
\text { index }\end{array}$ \\
\hline 100 & 54.5 & 39.2 & 6.3 & 1.39 & $2.09 \pm 0,04$ \\
\hline 200 & 62.5 & 34.2 & 3.3 & 1.82 & $2.30 \pm 0,04$ \\
\hline 300 & 62 & 30.5 & 7.5 & 2.03 & $2.39 \pm 0,05$ \\
\hline
\end{tabular}

As seen in the table, a rise of the RF power of deposition results in an increase of oxygen-to-titanium ratio in the films, which at 300 Watt acquires approximately that of titanium dioxide. However, at the same time the chlorine content is substantially increased. Higher energy increases the number of chlorine atoms reacting with titanium atoms what results in an increasing chlorine concentration at higher values of plasma power $(7,5$ at. $\%$ for $300 \mathrm{~W})$. A consequence of different oxide stoichiometry is a strong diversification of refractive index values, which at $550 \mathrm{~nm}$ vary from 2,09 to 2,39 for 100 and $300 \mathrm{~W}$ of plasma power respectively.

Using the above data, and keeping in mind that 300 Watt of RF power proved to be destructive for the polyester substrate, the material deposited at 200 Watt was selected as a titanium dioxide type high refractive index component of the filter. Deposition rate of this material amounts to $5 \mathrm{~nm}$ per minute. Figure 5 presents the optical quality of this material, in the form of its transmission spectrum.

3.3. Filter simulation. For the purpose of testing both the manufacture process of stack interference filter on the polyester support and the applicability of the selected materials, a relatively simple construction was chosen. The designed structure was a nine layer system consisting of five films of high graded refractive index (titanium dioxide type) separated by four layers of low graded refractive index (silicon dioxide type) with schematic description PET/(HL $)^{4} \mathrm{H} /$ Air. The system was simulated with the help of the TFCalc ${ }^{\mathrm{TM}} 3.5$ software and the result of that simulation is presented in Fig. 7.

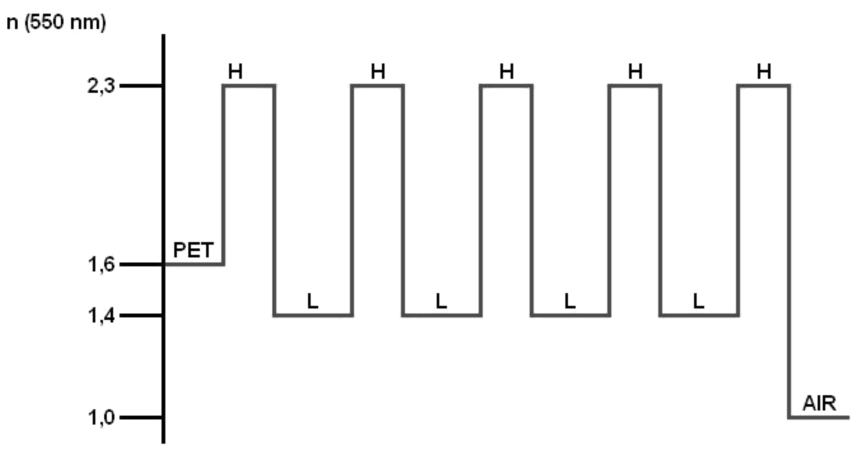

Fig. 7. Refractive index profile of the simulated HR filter

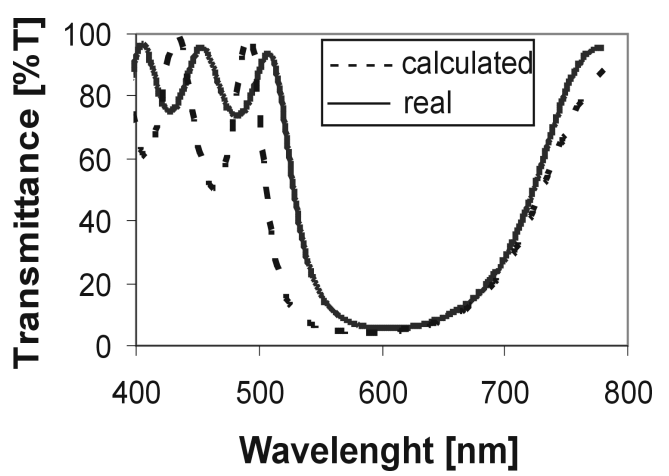

Fig. 8. Transmittance spectrum of the designed system resulting from the TFCalc ${ }^{\mathrm{TM}}$ simulation and of the real filter structure

The theoretical transmittance spectrum of the discussed filter, simulated within the visible range, is presented in Fig. 8. 
As far as the optical parameters of this filter are concerned, its minimum transmittance is $3.9 \%$ at $583 \mathrm{~nm}$ and maximum transmittance (at $433 \mathrm{~nm}$ ) amounts to $99.8 \%$. The thickness of every titanium dioxide layer is $50 \mathrm{~nm}$ (QWOT -0.84 for $\left.\mathrm{n}_{550}-2.3\right)$ while that of every silicon dioxide layer is $135 \mathrm{~nm}$ (QWOT - 1.37 for $\mathrm{n}_{550}-1.4$ ).

The colors of the designed filter, according to the international standard C.I.E. Color System, we also computed using the same software. The result of this computation is presented in Fig. 9.

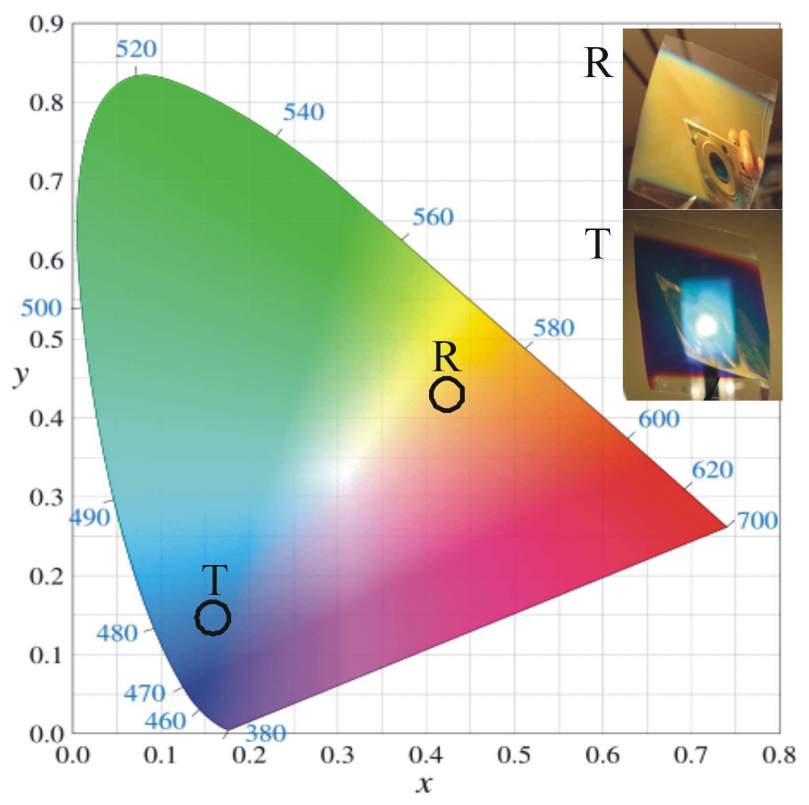

Fig. 9. A chromatic diagram with color coordinates of light transmitted $(\mathrm{T})$ and reflected $(\mathrm{R})$ by the designed filter. The colors of the real filter in the reflected $(\mathrm{R})$ and transmitted $(\mathrm{T})$ light are presented in the window

3.4. Filter preparation. Taking into account all the above findings, the designed optical filter was manufactured. In order to improve adhesion, prior to depositions, PET foil was exposed to argon plasma etching pretreatment. This process was carried out for 5 minutes at the RF power of $100 \mathrm{~W}$ and with the argon flow of $20 \mathrm{sccm}$. As the next step, a $10 \mathrm{~nm}$ thick silicon dioxide layer was deposited before the actual production of an optical multilayer structure. This procedure helped to minimize an impact of oxygen plasma on polymer interface. A production of the designed filter was then carried out. All operations, including argon plasma etching and the deposition of protective silicon dioxide layer were performed in one vacuum run with 10 second long breaks separating deposition of each $\mathrm{TiO}_{2}$ film from that of $\mathrm{SiO}_{2}$ film and vice versa. An electron scanning micrograph of the cross section of so manufactured system is shown in Fig. 10, while Fig. 8 presents its optical transmittance spectrum.

As seen in Fig. 8, the results of optical properties obtained for the real structure slightly differ from those simulated with the help of TFCalc ${ }^{\mathrm{TM}} 3.5$ software, with minimum transmittance $5.3 \%$ at $603 \mathrm{~nm}$ and maximum transmittance $96.6 \%$ at
$406 \mathrm{~nm}$. Figure 9 presents in the window the colors of the actual filter in both reflected (R) and transmitted (T) light.

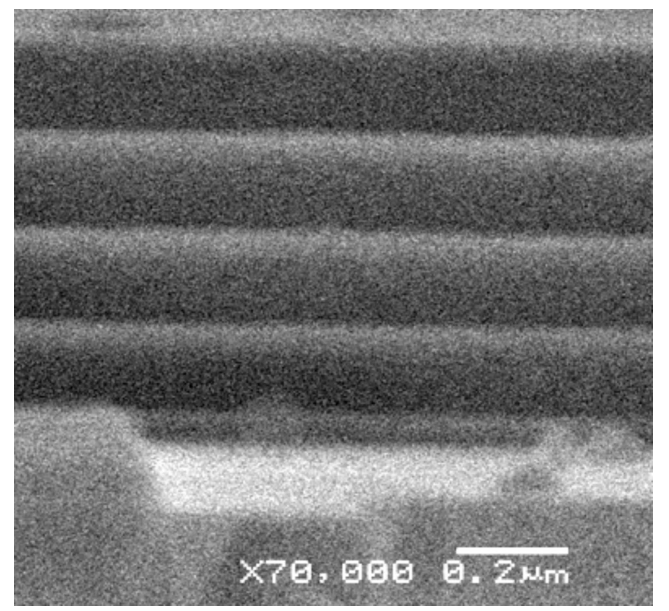

Fig. 10. An electron scanning micrograph of the cross section of the real filter structure

\section{Discussion and conclusions}

Titanium dioxide films from titanium tetrachloride/oxygen mixture and silicon dioxide films from hexamethyldisiloxane/oxygen were produced for optical applications on a poly(ethylene terephtalate) (PET) substrate, using the PECVD technique. The best results were obtained for $200 \mathrm{~W}$ of RF power for both materials. Higher energetic conditions lead to increase of defects number and polymer surface degradation.

Selected materials were used to produce high reflectance filter using $\mathrm{TiO}_{2}$ as high grade material and $\mathrm{SiO}_{2}$ as a low graded one on the same polymer substrate. Before actual deposition polymer surface was exposed on plasma etching pretreatment as it was proved to significantly improve adhesion of first layer to polymer substrate.

Although the design of the filter had required that the high refractive index material should constitute both outermost layers of the optical structure, the polymer/filter interphase of the actual device was made of a very thin film of low refractive index material. This was done on purpose, in order to minimize the effect of degradation of polyester substrate with oxygen plasma. Since the deposition rate of silicon dioxide is nearly three times higher than that of titanium dioxide, by doing so it took much shorter time to deposit a protective barrier layer, shielding the polymer surface from an initial degradation by reactive oxygen species and aggressive precursor. As a result this degradation was much less extensive and the optical quality of the entire device was least imperiled.

An introduction of the additional layer, however, is a significant alteration of the original design and this may be one of the reasons why the transmittance spectrum of the real structure slightly differs from that of the simulated filter (Fig. 8).

Another reason for that discrepancy may be connected with an experimental error resulting from the spread of reproducibility of deposition rate results in both processes. Nevertheless, in spite of all these differences and inaccuracies, 
the presented results show beyond question that the PECVD technique constitutes as very useful tool for a preparation of multilayer stack interference optical filters on polymer substrates.

Acknowledgements. This work was entirely supported by the Polish Ministry of Science and Higher Education under the project code of 3 T08E 10829.

\section{REFERENCES}

[1] S. Larouche, H. Szymanowski, J.E. Klemberg-Sapieha, and L. Martinu, "Microstructure of plasma-deposited $\mathrm{SiO}_{2} / \mathrm{TiO}_{2}$ optical films", J. Vac. Sci. Techn. A 22 (4), 1200-1207 (2004).

[2] A. Gruniger and P. Rudolf von Rohr, "Deposition of $\mathrm{SiO}_{2}$-like diffusion barriers on PET and paper by PECVD", Surf. Coat. Techn. 174-175, 1043-1047 (2003).

[3] A. Bieder, A. Gruniger, and P. Rudolf von Rohr, "Deposition of $\mathrm{SiO}_{\mathrm{x}}$ diffusion barriers on flexible packaging materials by PECVD", Surf. Coat. Techn. 200, 928-931 (2005).

[4] R.J. Martin-Palma, R. Gago, V. Torres-Costa, P. FernandezHidalgo, U. Kreissig, and J.M. Martinez Duart, "Optical and compositional analysis of functional $\mathrm{SiO}_{\mathrm{x}} \mathrm{C}_{\mathrm{y}}: \mathrm{H}$ coatings on polymers", Thin Solid Films 515, 2493-2496 (2006).

[5] J.P. Masse, H. Szymanowski, O. Zabeida, A. Amassian, J.E. Klemberg-Sapieha, and L. Martinu, "Stability and effect of annealing on the optical properties of plasma-deposited $\mathrm{Ta}_{2} \mathrm{O}_{5}$ and $\mathrm{Nb}_{2} \mathrm{O}_{5}$ films", Thin Solid Films 515, 1674-1682 (2006).

[6] R.J.M. Palma, R. Gago, V. Torres-Costa, P.F. Hidalgo, U. Kreissig, and J.M.M. Duart, "Optical and compositional analysis of functional $\mathrm{SiO}_{\mathrm{x}} \mathrm{C}_{\mathrm{y}}: \mathrm{H}$ coatings on polymers", Thin Solid Films 515, 2493 (2006).

[7] S. Bauer, L. Klippe, U. Rothhaar, and M. Kuhr, "Optical multilayers for ultra-narrow bandpass filters fabricated by PICVD", Thin Solid Films 442, 189-193 (2003).

[8] D.A. Jaworske, "Characterization of silicon thin film deposited by e-beam", Thin Solid Films 332, 30-33 (1998).

[9] G.A. Neuman and R.L. Stewart-Davis, "The use of experimental design techniques to meet reflected color targets in pyrolytic low emissivity coatings", Thin Solid Films 308-309, 26-30 (1997).

[10] S. Eliahou-Niv, R. Dahan, and G. Golan, "Design and analysis of a novel tunable optical filter", Microelectr. J. 37, 302-307 (2006). 